Ingrid Kummels ${ }^{1}$

Freie Universität, Alemanha

\title{
"Adiós soccer, here comes fútbol!": transnacionalização de comunidades esportivas mexicanas nos Estados Unidos 2
}

Resumo: Este artigo discute a dinâmica esportiva de comunidades mexicanas nos Estados
Unidos no contexto do futebol. A partir da análise de grupos mexicanos que imigraram para o
território americano e de suas práticas futebolísticas (de resistência), esta pesquisa se questiona
se estaríamos presenciando uma "latino-americanização" esportiva dos EUA através do futebol.
Como contrarresposta a uma homogeneização e subordinação, os mexicanos-americanos (e,
por extensão, os latinos em geral) criaram novas práticas culturais (e, dentre elas, as práticas
esportivas) que amalgamam tradições mexicanas com valores da sociedade estadunidense,
constituindo, assim, um terceiro espaço (a third space) que transpõe as fronteiras de ambos os
Estados nacionais. O presente artigo, portanto, analisa por que um crescente número de
imigrantes reforça as relações com suas comunidades de origem no México através da
(re)criação de um universo futebolístico próprio, expressando, com isso, uma "mexicanidade
transnacional" que não é "harmônica", mas é marcada por linhas de conflito. Nessa "nova
mexicanidade" manifestam-se conflitos de gênero, de classe e étnicos, locais e nacionais, que
se dão simultaneamente nos EUA e no México, e que se influenciam mutuamente. Palavras-chave: futebol hispânico; migração internacional; transnacionalização; "mexicanidades".

Copyright (C) 2011 by Revista Estudos Feministas.

1 Ingrid Kummels é professora doutora de Antropologia Social e Cultural no Instituto de Estudos Latino-Americanos (LAI) da Freie Universität (Universidade Livre), em Berlim, Alemanha.

2 Artigo traduzido do espanhol, reescrito em português e revisado por Wagner Xavier de Camargo. O artigo original - "Adiós soccer, here comes fútbol!: la transnacio-
São chamados de Necaxa, Tlatizapan, El Aguaje, Morelia, Toros ou Pumitas. Nos últimos anos centenas de clubes amadores de futebol proliferam-se por todas as partes. Isso tem ocorrido nos Estados Unidos (EUA), país em que esportes como beisebol, futebol americano e basquetebol têm, tradicional e historicamente, dominado a cena esportiva nacional. Dados clubes, que trazem nomes das comunidades de origem mexicana de jogadores ou de equipes populares do México, atualmente caracterizam a paisagem urbana com pelejas futebolísticas dominicais, tanto em grandes cidades das costas leste e oeste dos EUA 
nalización de comunidades deportivas mexicanas en los Estados Unidos" - foi publicado na Revista Ibero-Americana, v. VII, $\mathrm{n}$. 27, p. 101-116, 2007. Parte do título original é mantida, primeiro por trazer nela mesma as noções de transitoriedade e transposição do espanhol ao inglês (nos termos "adiós" e "here comes"), que são importantes no artigo, e, segundo, por apresentar um mesmo esporte entendido não apenas por dois universos linguísticos distintos ("soccer" e "fútbol"), mas por concepções de jogo bastante diferentes, vigorantes entre mexicanos e norte-americanos.

${ }^{3}$ ALIANZA DEL FÚTBOL, 2006.

${ }^{4}$ Matt REED, 2006, p. 1.

${ }^{5}$ COPA LOWE'S, 2006.

${ }^{6}$ REED, 2006, p. 3.

7 Juan Javier PESCADOR, 2004; e Christopher SHINN, 2002. quanto nas da região sul e também naquelas do cinturão industrial do entorno dos Grandes Lagos.

Nessas regiões, tais equipes associam-se em ligas próprias, independentes das ligas anglo-saxãs. Um exemplo é a Alianza de Fútbol Hispano, fundada em 2004, a qual se vangloria de representar 200 mil jogadores de futebol e suas famílias em todo o território estadunidense. ${ }^{3}$ Em outros aspectos, esses grupos formam um mundo esportivo à parte, uma vez que o futebol hispânico (hispanic soccer) é jogado de acordo com regras e estilos distintos da variante 'gringa' (ou norte-americana). Alex Flores, presidente da Liga de Fútbol Inter Latinos, assim explica: "Como nós latinos não somos muito altos, jogamos mais próximos ao solo, com toques mais curtos e muitos passes, sem chutes longos ou mesmo jogo aéreo, características do jogo anglo-saxão". ${ }^{4}$

Estaríamos presenciando uma "latino-americanização" esportiva dos EUA através do futebol? E, em caso afirmativo, isso ocorreria pois os migrantes mexicanos seriam ferrenhamente apegados às tradições e também às identificações esportivas de seu país de origem? Se observarmos detidamente tal fenômeno, a simples cadeia causal se complexifica: nativos mexicanos habitantes dos $\mathrm{EUA}=$ mesmas preferências esportivas que os mexicanos = futebol como esporte nacional.

Já há algum tempo certas empresas norte-americanas também intervêm no mundo do futebol latino. Há três anos, por exemplo, a famosa Lowe's - do setor de decoração de interiores - patrocina um campeonato no qual várias equipes masculinas (de jovens e de adultos hispânicos) se enfrentam em 11 cidades, em sistema de alternância entre elas, por semanas seguidas. Nas finais da Copa Lowe's, equipes semiprofissionais jogam contra as profissionais mexicanas propriamente ditas. ${ }^{5}$ Mike Robinson, diretor-geral da empresa de marketing La Verdad, de Cincinnati, destaca por que também outras companhias norte-americanas investem nesse tipo de torneio nacional: "O segredo é cooptar hispânicos onde normalmente se encontram. Eles estão em quadras e não em centros comerciais que têm botiques de luxo". 6

Por outro lado, o governo mexicano também dirige suas atenções aos migrantes futebolistas. Desde fins dos anos 1990 tem organizado, para os mexicanos esportistas amadores, a Copa México dentro dos EUA. ${ }^{7}$ Além disso, o excêntrico empresário Jorge Vergara, de Guadalajara, pela primeira vez montou uma equipe de futebol norte-americana, vendendo-a como um ícone desportivo do patrimônio cultural mexicano. Seu time Chivas USA compete, desde 2005, na Liga Principal de Futebol dos EUA (US Major League Soccer - MLS) com outras equipes estrelas dos EUA. A intenção 
${ }^{8}$ CHIVAS USA, 2006.

9 PESCADOR, 2004.

${ }^{10}$ Jorge IBER e Samuel REGALADO,
2007.

11 Emprego o termo "originários do México" da mesma forma com que se utiliza na atual estatística americana mexican ou of mexican origin, ou seja, como um termo coletivo, o qual inclui tanto os descendentes dos mexicanos que foram naturalizados como consequência da guerra entre México e EUA de 1846 a 1848 quanto os cidadãos nascidos ou naturalizados nos EUA, os quais têm uma ascendência mexicana (mexican americans), e até mesmo os recentes imigrantes sem documentos (US-Mexicans, vulgarmente denominados"illegal aliens"). Sob a designação "hispânicos" (hispanics) incluemse pessoas de países latinos ou luso-americanos. Apesar disso, esses termos coletivos não se afinam com as autorrepresentações e autoatribuições dos atores, suas diferentes situações de interesse e a consequente complexidade das interações sociais, como mostraremos no transcurso deste artigo. Os envolvidos preferem o termo coletivo latinos ou latinas em lugar de hispânicos (hispanics).

12 Por exemplo, Samuel HUNTINGTON, 2005.

13 O termo "mexicano étnico" agrupa os originários do México nos EUA e os cidadãos mexicanos propriamente ditos. por trás dessa ação é estimular os hispânicos a se identificarem com a equipe e, por meio de suas devoções ao esporte, influenciarem a competitividade e a qualidade técnica no interior da MLS, convertendo os EUA em uma nação do futebol. ${ }^{8}$

\section{Esporte, migração e "mexicanidades"}

Grupos de atores sociais (de ambos os lados da fronteira México-EUA) interferem nesse hispanic soccer, e isso prova que o gramado futebolístico se converteu em um espaço central no qual se colocam em cena e se negociam questões de identidades (nacionais) e organizações sociais, assim como é palco de integração cultural. ${ }^{9}$ Também outros esportes dos mexicanos-americanos são expressão de novas realidades demográficas, sociais e econômicas nos EUA, como mostra uma primeira compilação acerca do tema. ${ }^{10} \mathrm{~A}$ explicação para isso é a rápida mudança das coordenadas da migração mexicana, que desde os anos 1970 cresceu estrondosamente. Atualmente, os cerca de 27 milhões de mexicanos representam o maior grupo imigrante dos EUA, representando $9 \%$ da população total. Devido à complexa combinação de diversos fatores, tal corrente migratória continua em franca ascensão. Desde os anos 1990, sobretudo, muitos desses migrantes se deslocam a novos destinos na costa leste e no sudeste dos EUA, fato que tem transformado, substancialmente, a composição e a dinâmica étnicas nessas regiões. Além disso, dadas as características das ondas migratórias, tanto os grupos denominados "hispânicos" quanto os chamados de "mexicanos", ou "mexicanos-americanos", são, em realidade, grupos muito heterogêneos. ${ }^{11}$

Cientistas e políticos populistas de direita, por sua vez, instrumentalizam homogeneizações em tais categorias a fim de provocar temores sobre "a" população estadunidense ante uma suposta transformação cultural nociva da própria sociedade. ${ }^{12}$ De outra parte, cientistas "transnacionalistas" argumentam que, com a ajuda de novas práticas culturais, os mexicanos étnicos ${ }^{13}$ driblam as intervenções dos Estados nacionais - tanto de seu país de origem como do país de destino -, escapando, dessa forma, da discriminação e da subordinação de classe (e "racial") na sociedade norte-americana. Habitantes de grandes cidades (e mesmo de povoados) no México mantêm relações sociais duradouras com seus parentes e amigos nos EUA, impulsionadas pela globalização dos mercados de trabalho, por novos meios de comunicação e por dinâmicas globais de difusão cultural. Consequentemente, os imigrantes são ativos, tomam decisões, assim como formam 
14 Linda BASCH, Nina Glick SCHILLER e Cristina Szanton BLANC, 1994.

${ }^{15}$ David GUTIERREZ, 1999.

${ }^{16}$ GUTIERREZ, 1999, p. 483.

17 PESCADOR, 2004 e 2007. novas comunidades dentro de um espaço transnacional constituído por tais redes. ${ }^{14}$

David Gutierrez ${ }^{15}$ faz menção a uma partida de futebol que aconteceu em fevereiro de 1998, em Los Angeles. No momento em que a equipe nacional mexicana ganhou dos EUA pelo placar de 1:0, a maioria dos mais de $90 \mathrm{mil}$ espectadores do estádio gritava de alegria. Alguns jogadores do time norte-americano se queixaram amargamente de que aquela não era uma partida "em casa", pois o jogo aconteceu em uma cidade onde se estima em $50 \%$ o número de hispânicos na composição da população. Para o autor, o "drama simbólico" dessa partida é sinal da atual "desestabilização de concepções uniformes de comunidade, cultura, nacionalidade $e$, inclusive, da ideia de 'nação territorial'". ${ }^{16}$ Como resposta a sua homogeneização e subordinação, os imigrantes mexicanos criaram novas práticas culturais que amalgamam suas tradições com valores da sociedade estadunidense, constituindo, assim, um terceiro espaço (a third space) que transpõe as fronteiras de ambos os Estados nacionais.

Na mesma linha argumentativa acham-se os trabalhos sobre a cultura mexicana do futebol na região dos Grandes Lagos, do lado americano. ${ }^{17}$ Desde os anos 1920, os migrantes mexicanos se organizam em agrupamentos de vizinhos, e em pequenas comunidades, por meio do futebol. Mediante a cooperação esportiva com grupos de imigrantes europeus (que trouxeram pela primeira vez o futebol àquela área), fizeram-se respeitar e são apreciados pela sociedade em geral. O autor sublinha que tais atores agregaram ao ócio futebolístico valores da classe trabalhadora estadunidense, conferindo-lhe uma nova interpretação. Nesse processo ressaltaram valores como disciplina, masculinidade, individualidade e competência. Posto isso, Pescador, com razão, desvirtua a hipótese de que o boom futebolístico nos EUA deve-se ao fato de que os praticantes imigrantes seguiriam ferrenhamente as tradições de seu país de origem. Em contrapartida, não oferece uma explicação sobre a forte e pronunciada influência mexicana no futebol desenvolvido nos EUA. Os jogadores desse hispanic soccer nominam seus times segundo suas comunidades de origem e até mesmo com nomes de equipes profissionais mexicanas; e com frequência, inclusive, recrutam novos talentos esportivos do país vizinho. Assim, resta a questão: por que um crescente número de imigrantes reforça as relações com suas comunidades de origem (e mesmo sua pátria) por meio do futebol?

Uma análise que toma o esporte como ponto de partida pode desvelar dinâmicas da identidade social nos EUA latino-americanizados. Pesquisas sobre etnologia do 
18 Pierre BOURDIEU, 1992; e Jeremy MACCLANCY, 1996.

${ }^{19}$ Cyril Lionel JAMES, 1963, p. 23.

${ }^{20}$ Louis PÉREZ, 1994, p. 500.

21 Em seu Programa para uma Sociologia do Esporte, Bourdieu (1992, p. 195) destaca que, "[...] para compreender um esporte de qualquer tipo, [...] é necessário discernir a posição que ocupa dentro do espaço dos diferentes tipos de esporte". esporte, com vieses históricos e transnacionais, mostram de que modo atores sociais - particularmente sob os efeitos da globalização - utilizam a prática esportiva para dirimir conflitos sociais pelo controle do corpo físico e como, simultaneamente, contestam as identidades sociais, os papéis de gênero, as atribuições étnicas e nacionais existentes, renegociando-os. ${ }^{18}$ Tanto a classe dominante como as dominadas souberam aproveitar as possibilidades que oferece o esporte como ordem de conhecimento que se transmite através do corpo, ou seja, o esporte é mais acessível do que conhecimentos que estão mais estreitamente articulados com uma formação institucional; e também o esporte goza de uma grande aceitação, seja porque é percebido geralmente como 'apolítico', seja por ser visto alijado de interesses econômicos.

Os representantes das potências coloniais trataram, a miúde, de evitar de antemão a resistência dos colonizados, tentando pressioná-los por meio de seu esquema de "raças", nações e classes, justamente por meio de práticas cotidianas como o esporte. De outra parte, os oprimidos transformaram os esportes introduzidos em espaços sociais a fim de "colocar em cena os antagonismos de situações coloniais e pós-coloniais e de lhes dar uma solução imaginária". ${ }^{19}$ Por assim dizer, os esportistas aficionados "reinventam-se" através da prática esportiva, "conscientemente como atores de mudança cultural". ${ }^{20}$

Dessa forma, por meio do futebol jogado nos EUA, poder-se-ia dizer que os esportistas hispânicos efetuam uma inversão simbólica comparável a das relações de poder no âmbito societal? Expressariam, através daquela modalidade, um novo conceito de "mexicanidade"? A seguir abordaremos tais questões e, além disso, partindo de uma perspectiva histórica do contexto dos anos 1940 e da atualidade, analisaremos o desenvolvimento do futebol tanto no México quanto nos EUA - particularmente em respeito ao segundo potencial "esporte nacional" mexicano: o beisebol. ${ }^{21}$

\section{Apropriações regionais do beisebol e do futebol: o caminho mexicano em direção a um esporte nacional}

A instrumentalização do futebol (por parte de diferentes grupos de atores), descrita anteriormente, transmite a imagem de uma longa tradição futebolística nacional. No entanto, se analisado detidamente, o México é um país dividido em relação às suas paixões esportivas, mesmo quando o futebol tem ganhado espaço: somente no centro do país há um domínio indiscutível do esporte-rei; o norte e 
22 Coletânea de entrevistas com Obrador sobre as relações com Carlos Slim, consultar ETECÉTERA, 2006.

${ }^{23}$ REGALADO, 1998.

24 "Porfiriato" ou "Porfirismo", como é conhecido na história do México, é o período de 1884 a 1911 em que, devido a mudanças na constituição nacional, o militar José de la Cruz Porfirio Díaz Mory presidiu o país (Nota do Tradutor).

${ }^{25}$ José ALAMILLO, 2007, p. 52.

${ }^{26}$ ALAMILLO, 2007. o sudeste mexicanos mostram uma preferência pelo beisebol marcada pelo regionalismo. Se efetuado um upgrade temporal, hoje tal questão é atravessada pela política e pela economia: em 2006, por exemplo, o candidato à presidência Andrés Manuel López Obrador - originário de Tabasco - pediu publicamente ao empresário das telecomunicações da capital, Carlos Slim, que sua empresa (Telmex) patrocinasse, além das mais de 15 mil equipes de futebol, também os times de beisebol. ${ }^{22}$

Aqui se faz necessária uma explicação sobre por que o beisebol, que nos anos 1950 ainda superava o futebol em popularidade, posteriormente, acaba se tornando um esporte secundário. Pouco tempo depois que Alexander Joy Cartwright propôs as regras do jogo moderno em Nova lorque no século XIX, o beisebol também se converteu em um esporte local na Península de Yucatán. Trabalhadores cubanos adotaram-no por volta de 1860, e tanto integrantes da elite nacional yucateca (que em parte haviam estado nos EUA) como também muitos outros trabalhadores passaram a praticá-lo rapidamente. ${ }^{23}$

Ao norte do México algumas companhias norteamericanas, que durante o Porfiriato ${ }^{24}$ investiram na mineração e na construção ferroviária, patrocinaram o beisebol com o intuito de transmitir aos empregados valores como espírito de equipe, considerados por elas imprescindíveis para a construção de uma moderna sociedade industrial. Os habitantes dessa região adotaram o esporte rapidamente como parte de um estilo de vida moderno, e Wallace Thompson (editor de uma revista) constatou: "foi o que mais próximo chegou o México de ter um esporte 'nacional'". ${ }^{25}$ Além disso, nos estados norteamericanos próximos da fronteira, constelações de poder e motivações semelhantes contribuíram, desde os anos 1920, para que migrantes de origem mexicana (em sua maioria, trabalhadores da agroindústria) jogassem, sobretudo, beisebol. ${ }^{26}$

Empresas - como a produtora de cítricos Sunkist -, patrocinavam a criação de equipes de beisebol entre os trabalhadores mexicanos temporários com o intuito de incrementar a produtividade desses e angariar suas respectivas lealdades. No sul da Califórnia, por exemplo, os habitantes de comunidades mexicanas e de bairros urbanos logo fundaram inúmeros clubes, que jogavam entre si.

Esse perceptível isolamento pode ser relacionado com a prática da segregação, própria do mundo esportivo dos EUA. Até 1947 negava-se o acesso de jogadores afroamericanos e latinos de pele escura aos clubes profissionais que competiam na MLS. Entretanto, com a ajuda de equipes de beisebol próprias, o grupo heterogêneo de mexicanos 
${ }^{27}$ ALAMILLO, 2007.

28 Mais detalhes sobre as manobras efetuadas, consultar Alan KLEIN, 1997, p. 66-113. que haviam sido naturalizados como consequência da guerra entre México e EUA, os mexicanos-americanos e os imigrantes recentes reposicionaram-se diante dos conflitos "raciais" e de classe. Através do beisebol, tais indivíduos manifestaram uma consciência étnica comum, uma solidariedade comunitária e um comportamento masculino que, dessa forma, se faziam respeitar. Além disso, ligaram o beisebol às suas vidas cotidianas nos EUA. Os imigrantes (homens na maior proporção) reproduziam e reforçavam, na arena masculina do beisebol, a dominação masculina do mundo laboral agroindustrial. ${ }^{27}$

Os mexicanos de ambos os lados da fronteira transformaram o beisebol, nesse período, em um fenômeno transnacional. Equipes mexicanas cruzavam regularmente a fronteira a fim de participarem de competições no sudoeste dos EUA. Jorge Pasquel, um empresário milionário da capital mexicana, patrocinou o beisebol do país asteca com grande apoio financeiro, a partir dos anos 1940, influenciado por um sentimento de nacionalismo mexicano e pela ideia de desafiar os EUA, no âmbito esportivo, de igual para igual. Apropriando-se da prática de segregação nos EUA, comprou jogadores-estrelas afro-americanos para equipes mexicanas; em 1949, inclusive, passou a alistar jogadores brancos. Dessa forma, conseguiu um rápido incremento na qualidade - e mesmo na popularidade - da Liga Mexicana de Beisebol. Mexicanos de ambas as partes da fronteira expressaram, por meio de seus apoios a essa liga, um sentimento de pertencimento transnacional. Por certo tempo, a manobra empreendida pelo empresário funcionou a contento. Contudo, sua política agressiva de recrutamento de jogadores de outros clubes provocou uma contramedida por parte das ligas estadunidenses, que frearam seu ambicioso projeto. ${ }^{28}$

O futebol, naquela época um esporte sem importância tanto no México quanto entre os migrantes nos EUA, impôs-se, primeiramente, em algumas cidades industriais do centro do México nas quais as empresas britânicas possuíam hegemonia na mineração e na indústria têxtil. No entanto, em meados do século XX, trabalhadores britânicos especializados jogavam entre si do mesmo modo como já ocorria em outros lugares da América Latina. Nos anos 1920, a exclusivamente britânica Liga Mexicana de Football sofreu uma derrocada decisiva no momento em que, pela primeira vez, clubes espanhóis passaram em quantidade os britânicos.

Os clubes mexicanos, por sua vez, também se multiplicaram, principalmente graças a membros de classes altas que haviam estudado (ou trabalhado) em países europeus. Algumas companhias, sindicatos e instituições 
29 PESCADOR, 2007.

30 PESCADOR, 2007.

${ }^{31}$ Literalmente "bola no pé". O balompié é um antecessor do futebol contemporâneo, de origem e influência espanholas (Nota do Tradutor). governamentais mexicanos financiaram tais clubes. Quando futebolistas espanhóis e mexicanos começaram a manifestar orgulho nacional através das partidas e menos ressentimentos entre si, o futebol experimentou uma fase de intensa popularidade. A disputa entre esses grupos estava intimamente relacionada com a posição da Espanha como potência colonial. Os mexicanos atualizaram esse antagonismo em vista do crescimento da comunidade espanhola e sob os auspícios de seu predomínio em determinados setores econômicos. Dois clubes de classe baixa na capital - Necaxa e Atlante - ficaram bastante populares justamente por triunfar sobre equipes espanholas e até hoje continuam sendo importantes. Com o tempo, as equipes de futebol dirimiram menos os antagonismos étnicos do que os de classe. ${ }^{29}$

Nos anos 1960, o futebol ganhou em popularidade em relação ao beisebol em terras mexicanas, fenômeno no qual a televisão, o novo meio de comunicação da época, exerceu papel fundamental. Por exemplo, quando em 1950 a primeira emissora começou a trabalhar na Cidade do México, inclusive esportes como o boxe, as corridas de touros e mesmo a luta livre cativaram muitos seguidores. Não obstante, os esportes que se adaptavam com grande rapidez à transmissão televisiva cresciam em importância.

Além disso, a televisão estabelecida na capital demonstrava maior interesse de difusão de esportes que eram mais populares no centro do país do que nas demais áreas, apoiando financeiramente, sobretudo, campeonatos nacionais com vistas a transmitir os jogos. Esse processo a favor do futebol experimentou um estímulo adicional com as celebrações dos Jogos Olímpicos de 1968 e da Copa do Mundo de Futebol de 1970, ambos na Cidade do México, mediante os quais as imagens do futebol obtiveram um marco de prestígio e foram difundidas, de forma intensiva e em nível suprarregional, através do então popular meio de transmissão: a televisão. ${ }^{30}$

\section{Mundos esportivos paralelos nos EUA e práticas de empoderamento}

No passado o futebol tinha um status marginal e de menor importância também nos bairros mexicanos do meiooeste americano. Uma das razões de tal fato era de a maioria dos imigrantes mexicanos originarem-se de comunidades rurais onde, costumeiramente, se jogava o balompié. ${ }^{31}$ Apesar disso, Chicago era exceção no cenário nacional norte-americano: as estruturas esportivas e as de atividades de lazer existentes na cidade giravam em torno do futebol e tinham sido fundadas por britânicos e outros imigrantes 
32 Gabriela ARREDONDO e Derek VAILLANT, 2006.

${ }^{33}$ NSL CHICAGO, 2006. europeus (como irlandeses, checos, poloneses e croatas). A cidade até hoje tem a liga de futebol mais antiga dos EUAe segue sendo o centro nacional da modalidade. ${ }^{32}$

Os imigrantes mexicanos em Chicago se adaptaram a essa estrutura e fundaram, no ano de 1927, o clube futebolístico Necaxa, em uma referência histórica a um que fora criado em 1923, na capital mexicana. Os membros desse clube se associaram, nos anos 1940, a uma liga amadora de imigrantes europeus - a Liga Nacional de Futebol de Chicago (Chicago National Soccer League - CNSL), a qual se converte em uma liga mexicana-europeia. Assim, dentro dessa organização surgiu uma estrutura competitiva que seguiu uma lógica nacional similar àquela existente (à época) entre equipes mexicanas e espanholas no México: a equipe mexicana competia com as demais compostas de imigrantes europeus. Isso ocorreu com êxito, e tal equipe subiu até a divisão mais alta daquela liga. Contudo, atualmente na CNSL enfrentam-se, por exemplo, Deportes Colomex com FC Romania ou com FK Bosanska Dubica, ${ }^{33}$ equipes amadoras ou semiprofissionais que não são tão expressivas. As rivalidades esportivas se desenvolveram ao longo das mesmas linhas étnicas que conformavam o mundo laboral da indústria pesada do aço, em que mexicanos e europeus competiam aguerridamente por postos de trabalho. O processo de integração nas ligas americanas de futebol foi mais fácil para os migrantes que o praticavam do que para aqueles que jogavam beisebol, modalidade que se negou, formal e informalmente, a ceder espaço à participação desses indivíduos.

Além disso, os imigrantes usavam os clubes de futebol (como o Necaxa, por exemplo) para reestruturarem seus momentos de ócio e lazer, ampliando-os com atividades sociais que iam além do esporte em si. As equipes, os meios de comunicação locais, os empresários mexicanos e uma incipiente indústria "étnica" do entretenimento promoviamse mutuamente em tal desenvolvimento, já que cada um se beneficiava da cooperação. Algumas empresas, visando principalmente à população mexicana (sobretudo restaurantes, lojas de cosméticos, charcutarias, ${ }^{34}$ armazéns de bebidas e emissoras de rádio em língua espanhola), cofinanciavam os clubes de futebol, desejosos por conquistar os fanáticos do esporte como possíveis clientes. Os novos modelos de consumo, dessa forma, participavam do modus cultural mexicano, mas se orientavam por influências norte-americanas, formando parte de um novo estilo de vida dos migrantes e de seu estabelecimento duradouro nos EUA. ${ }^{35}$

Paralelamente alguns imigrantes mexicanos se utilizaram dos clubes esportivos para construir (ou reforçar) 
36 Douglas MASSEY et al., 1987.

37 Atravessador da fronteira México-EUA. Geralmente cobra por "cabeça" para ajudar no cruzamento ilegal da fronteira (Nota do Tradutor).

38 Ver também Michael RILEY, 2003.

${ }^{39}$ ALAMILLO, 2007; e PESCADOR, 2004.

40 Joel COHEN, 2006.

${ }^{41}$ PESCADOR, 2004. redes transnacionais duradouras entre seu país de origem e a comunidade de destino. Tais redes sociais facilitaram e promoveram a decisão de migrar e, portanto, aceleraram, no transcurso de uma geração, a continuidade do movimento migratório.

Douglas Massey e colaboradores ${ }^{36}$ descrevem esse processo para o caso dos emigrantes da cidade industrial de Santiago, Jalisco, que se concentraram, principalmente, em Los Angeles (LA). A fundação oficial de um clube de futebol lhes permitiu cobrar taxas de filiação aos membros e melhorar rapidamente a qualidade da equipe amadora. Por sua vez, as vitórias obtidas em jogos motivaram a quase totalidade dos oriundos de Santiago a aderirem ao clube, que conseguiu assegurar um campo de treinamento em um parque público de LA, o qual se tornou um espaço de encontros fixos dos migrantes residentes da (e também dos que chegavam à) cidade. Mais tarde, compraram casas nas redondezas, transformando o espaço, ao longo dos anos, em "seu" bairro. Motivados pela pressão de êxito, os treinadores da equipe de futebol buscaram na comunidade de origem no México mais jogadores com talento, inclusive Ihes pagavam o "coyote" 37 para que conseguissem transladar o espaço da fronteira e fazer parte de sua equipe. ${ }^{38}$

Os mexicanos-americanos conquistaram, através do futebol e de outros esportes jogados em equipe, um espaço social de convívio e, através desse, atacaram as estruturas de ócio existentes nos EUA, modificando-as. ${ }^{39}$ Antes da Segunda Guerra Mundial, justamente nos parques, nas piscinas e em outros estabelecimentos públicos ocorria a segregação social de acordo com o conceito de "raça" dominante, sendo o acesso negado aos mexicanos. Esses se viam obrigados a se deslocar para terrenos baldios ou para localidades agrícolas abandonadas. Até hoje em dia se discriminam (veladamente) jogadores de futebol hispânicos, negando-lhes acesso aos parques públicos de lazer e entretenimento. ${ }^{40}$

A falta de instalações atrativas para o tempo livre influenciou futebolistas mexicanos de Chicago e região a abandonarem a CNSL e a fundarem em 1968, pela primeira vez, uma liga própria que passou a ser chamada de Associação de Futebol Latino-Americano de Chicago (Chicago Latin American Soccer Association - Clasa). A decisão foi desencadeada pelo descontentamento dos futebolistas imigrantes mexicanos com o fato de que os delegados de origem europeia monopolizavam a liga $e$ favoreciam suas equipes. Através da Clasa, os mexicanos abriram caminho a trinta parques públicos e a mais de quarenta campos de futebol. ${ }^{41}$ Dessa maneira, transfor- 
maram os parques em lugares de encontros permanentes das famílias mexicanas de toda a região. Essas, por sua vez, estruturaram suas atividades recreacionais dominicais em torno das partidas de futebol aí organizadas, convertendo tais jogos em eventos centrais.

\section{A transnacionalização do futebol a partir da década de 1990}

Desde os anos 1990 a migração vinda da América Latina tem se intensificado: aproximadamente a metade dos oriundos do México e dos hispânicos que vivem nos EUA se moveu para esse país a partir dessa década. Tal onda migratória tem novas características: primeiro chegava, sobretudo, das regiões que se encontravam em guerra civil (notadamente Honduras, El Salvador, Guatemala e Colômbia) e, mais tarde, provinha do México e do Equador, países atravessados por intensas crises econômicas e financeiras.

Os imigrantes, por sua vez, vêm de países com uma clara preferência pelo futebol como esporte. Com respeito a esse aspecto, há que levar em conta a hipótese segundo a qual os latinos, atualmente, servem-se do futebol (esporte internacionalmente com grande apelo e bastante popular no hemisfério sul) para "sustentar uma conexão profunda e duradoura com a América Latina", que se torna um marco cultural a partir do qual eles forjam "um incipiente sentido

${ }^{42}$ SHINN, 2002, p. 41. de pátria em terras norte-americanas" ${ }^{22}$ Grande parte desses imigrantes se dirigem a cidades e regiões estadunidenses sem qualquer tradição de colonização de hispânicos. Entretanto, os migrantes de diferentes origens e de distintas gerações e classe sociais usam o futebol de modo intencional como um recurso que cria comunidade. Através da modalidade tentam melhorar a qualidade do tempo de lazer em suas novas áreas de moradia, fazer trabalho comunitário ou obter acesso a consumidores hispânicos. Além disso, o futebol também foi descoberto pelos trabalhadores comunais, pelos centros de formação, pelas organizações juvenis, pelas instituições sem fins lucrativos, pelas instituições sociais públicas, pelos meios de comunicação de massa e pelas empresas não étnicas. A atual política norte-americana, de sua parte, trata de integrar os migrantes que vivem há muito tempo no país com seus descendentes. Desse modo, recorre-se ao futebol dentro do espaço do trabalho comunitário fomentado pelo Estado a fim de agregar os latinos.

Pode-se, assim, levantar alguns dados quantitativos significativos que identificam o crescimento do futebol via comunidade latina como um boom: há uma década, a 
${ }^{43}$ REED, 2006, p. 1.

44 Grupos de jogadores bem jovens e inexperientes (Nota do Tradutor).

${ }^{45}$ Beer leagues é uma designação conferida aos campeonatos nos quais as equipes, ganhando ou perdendo, comemoram seus sucessos ou fracassos com o consumo de muita cerveja e outras bebidas alcóolicas. São jogos totalmente amadores em que a presença de uma dúzia de espectadores pode ser considerada uma "bilheteria" de sucesso. Não há glamour nem condições objetivas e estruturais favoráveis. Jogadores dessas ligas, na maioria das vezes, jogam com equipamentos precários, sem uniformes e mesmo sem calçados adequados (Nota do Tradutor).

${ }^{46}$ Patrick JONSSON, 2003.
Liga de Futebol Inter Latinos, com sede em Columbus (Ohio), reunia menos de uma dezena de equipes. Em 2006, por sua vez, contava com 92 times e 1.800 jogadores. Em Raleigh (Carolina do Norte), existia no ano de 2000 apenas uma liga hispânica. Em 2006, o número sobe para quatro ligas, que reuniam 40 equipes e 1.300 jogadores. Ao passo que as ligas próprias oferecem vantagens ao serem usadas como formas de empoderamento, as ligas separadas predominam tanto no âmbito amador como no semiprofissional. Dr. Tim Wallace, presidente da liga de Raleigh, explica: "há vinte anos se podia encontrar alguns clubes hispânicos isolados nas ligas gringas, mas agora se impõe o modelo das ligas separadas". ${ }^{43}$

Os grupos de atores heterogêneos produziram um mundo futebolístico de grande diversidade. Os novos imigrantes começam, minimamente, a jogar futebol sob condições semelhantes àquelas com que iniciaram os mexicanos, nos anos 1920: em contextos informais, nos chamados sandlot teams ${ }^{44}$ e beer leagues. ${ }^{45}$ Os recémimigrados utilizam a oportunidade de participação nessas equipes como primeiros contatos, estabelecimento de relações sociais, identificação de locais para se alojarem ou trabalharem e, sobretudo, para se inserirem como jogadores através da linguagem internacional do futebol. Um dos problemas mais urgentes de tais times é exatamente garantir o espaço da prática esportiva em um campo com dimensões regulamentares, em parques públicos urbanos. ${ }^{46}$ Tal empenho segue sendo uma importante motivação para a formalização das organizações de futebol e para a criação de ligas, cujos membros podem falar espanhol entre si e pagar contribuições mais baixas do que as que são costumeiramente cobradas nas ligas estadunidenses.

O outro extremo está conformado pelos mexicanosamericanos da primeira e da segunda gerações. Suas condições de vida nos EUA melhoraram demasiadamente, principalmente em decorrência do Ato de Controle e Reforma Imigratória (Immigration Reform and Control Act), de 1986, que promoveu a legalização dos migrantes que já viviam permanentemente no país, assim como o reagrupamento familiar. A antiga relação numérica entre homens e mulheres imigrantes (na qual os primeiros eram numericamente superiores) se equilibrou; a maioria deles vive em famílias e a tendência de uma permanência prolongada aumentou consideravelmente. Pode-se dizer que os imigrantes da primeira geração conseguiram certa prosperidade, ocupando com êxito determinados nichos econômicos de mercado, ao passo que a geração atual sofre com piores condições no que diz respeito à educação escolar, ao trabalho e ao perigo de se envolver em grupos delinquentes 
${ }^{47}$ Robert SMITH, 2005.

${ }^{48}$ COHEN, 2006.

49 Jesse AGUILAR, 2006.

50 CHRON, 2007.

${ }^{51}$ COPA TECATE, 2006.

52 PESCADOR, 2004. juvenis. ${ }^{47}$ Aqueles que conquistaram uma situação de bemestar contribuem com o boom futebolístico financiando as equipes. Eles esperam obter prestígio dentro da comunidade hispânica por meio da posse de uma equipe vencedora. Para tal propósito, investem em campos de treinamento, uniformes de futebol e seguros-saúde para jogadores, mesmo sem ter ainda a segurança de valer a pena do ponto de vista financeiro. ${ }^{48}$ Dessa forma, um empresário mexicanoamericano se permite financiar, por exemplo, a Díaz Mexican Soccer League, em Nova lorque (a qual leva seu nome), e o industrial Mario Calleros, em Chicago, faz o mesmo com a equipe El Nacional. Essa, por sua vez, conquistou em 2006 o primeiro lugar nos torneios nacionais da Copa Tecate e da Copa Lowe's. ${ }^{49}$

Empresas étnicas ou não étnicas, meios de comunicação hispânicos e grandes ligas cooperam na organização e no financiamento de campeonatos regionais e nacionais custosos. A cadeia de supermercados Food City e a cervejaria mexicana Tecate, entre outras, aproveitam os eventos nacionais como meios de publicidade para conquistar "o maior mercado hispânico do mundo". ${ }^{50} \mathrm{Na}$ Copa Tecate, o "maior campeonato de futebol hispânico", competiram em 2006 mais de 2.700 equipes em 22 cidades, tendo o El Nacional de Chicago ganhado a final e o prêmio de US\$ 15 mil. ${ }^{51}$ Tais competições desestabilizam a antiga estrutura de convicções das equipes amadoras de níveis local e regional: muitos jogadores viajam horas a fio, uma parte do ano, como semiprofissionais a fim de participarem em tais eventos, recebendo por jogo uma quantia fixa, apesar de não poderem contar unicamente com o futebol para sobreviverem.

Por outro lado, o Club México de Chicago é um exemplo da combinação de futebol com o trabalho comunitário e o trabalho com jovens. Carlos Cerrasco, oriundo do estado de Durango, participou das fundações tanto de uma organização comunitária para os latinos no estado de Illinois quanto do clube de futebol, em 1996,52 apesar do fato de Cerrasco não ter experiências com futebol nem com o trabalho com jovens. Tudo ocorreu, em verdade, quando seu filho entrou na adolescência e ele quis oferecer aos jovens uma alternativa em relação à criminalidade vigente nos grupos juvenis. Cerrasco, então, fundou o Club México como um espaço para práticas esportivas de adolescentes no oeste de Chicago, no bairro de Las Villitas, local de maior localização de imigrantes mexicanos do meio-oeste americano.

Ricardo Díaz, um ativista político de origem mexicana - que em 2006 organizou os protestos contra o recrudescimento das leis de imigração -, inaugurou, por sua vez, o 
${ }^{53}$ CITY PAPER, 2006.

${ }^{54}$ PESCADOR, 2004.

${ }^{55}$ No original encontramos menção a "población en edad de trabajar", que, do ponto de vista da geografia econômica, significa "população economicamente ativa" ou PEA (Nota do Tradutor). ${ }^{56} \mathrm{SMITH}, 2005$.

57 Ruben HERNÁNDEZ-LEON e Víctor ZUÑIGA, 2002. clube de futebol Amistad, no sul da Philadelphia, como "pretexto" para o trabalho comunitário. Mesmo sendo maioria, os recentes imigrantes mexicanos não contam com uma estrutura comunitária mínima, segundo Díaz. Portanto, o Amistad funciona, de acordo com ele, como um tipo de infraestrutura que lhe permite vislumbrar as necessidades de tais imigrantes e informá-los sobre o serviço médico gratuito e seus direitos ante as novas leis de imigração. ${ }^{53}$

Um sentimento de pertencimento entre o grupo heterogêneo de imigrantes apenas se cristaliza mediante um projeto comum. O interesse emerge rapidamente com relação ao país de origem, e tais comunidades engajamse em projetos de auxílio financeiro movidos pelos clubes de futebol. Os membros do Clube Ciudad Hidalgo, de Chicago, por exemplo, contribuem financeiramente, principalmente, com a cidade de mesmo nome, em Michoacán. Encarregaram-se da renovação ou da reconstrução da igreja nesse lugar, do colégio, do centro juvenil, da creche e da área de esportes. O rádio e a televisão de Chicago comunicam, frequentemente, seu compromisso social exemplar, fomentando, assim, o orgulho de ser membro do clube. ${ }^{54}$ Esse direcionamento da atenção em relação ao México não está motivado, em primeiro lugar, pela nostalgia. Como grande parte da população economicamente ativa ${ }^{55}$ vive nos EUA, as comunidades mexicanas exigem dos migrantes, cada vez mais, auxílios financeiros para a manutenção da própria comunidade. ${ }^{56}$

Sobretudo nos novos destinos migratórios, os imigrantes mexicanos atribuem ao futebol um papel-chave. Em Dalton, Geórgia (sudeste dos EUA) - que se vangloria de ser a 'capital mundial do carpete' -, durante um período de grande prosperidade na economia norte-americana e do consequente boom do setor relacionado à construção civil surgiu uma enorme demanda por mão de obra barata. Na década de 1990, no distrito mencionado, a porcentagem de hispânicos cresceu de 3 a 22\%; atualmente, a metade dos trabalhadores da indústria do carpete é hispânica. Em poucos anos, os imigrantes criaram (e praticamente do "zero") a Liga Mexicana de Futebol, uma organização de centenas de jogadores. Alguns migrantes, que antes se encontravam ativos nas ligas de futebol de Los Angeles, foram os responsáveis pela organização criteriosa, incluindo endereço próprio, aluguel de escritório e até contratação de um tesoureiro. Tal liga foi considerada um dos ganhos mais significativos da jovem comunidade. ${ }^{57}$ Segundo esses autores, isso mostraria como os atores usavam os recursos, as informações e o conhecimento que haviam adquirido como migrantes (temporários e permanentes) a fim de rapidamente edificar, em um novo contexto, estruturas comunitárias. 
58 Dale RUSSAKOFF, 2006.

59 COHEN, 2006.
Entretanto, pode-se dizer também que os empresários locais não hispânicos desempenharam um papel importante nessa bem-sucedida experiência. Eles patrocinaram a manutenção de vários campos de futebol com dinheiro da exploração da mão de obra barata dos recém-chegados: os trabalhadores imigrantes mexicanos, ao chegar, se conformam com salários baixos. Tal fato é bem distinto do que ocorre, por exemplo, com a geração dos trabalhadores localizada nos arredores dos Montes Apalaches, costa leste americana. Esses travam uma batalha judicial desde 2006 contra a produtora de carpetes Mohawk Industries, que é acusada por eles de contratar intencionalmente imigrantes ilegais mexicanos. ${ }^{58}$

Ainda que equipes hispânicas amadoras levem nomes de suas comunidades de origem, elas possuem um caráter bastante inclusivo e, tendo-se em conta o êxito esportivo, integram jogadores de uma série de nações, como, por exemplo, do México, do Brasil, da Guatemala, da Bósnia e da Somália. ${ }^{59}$ Isso nos adverte, previamente, para não olharmos os clubes com lentes étnicas. Segundo Marcos García - presidente de uma liga de futebol hispânica com uma maioria de salvadorenhos da região de Boston -, os torcedores fanáticos se orientam por um patriotismo local em relação à equipe de sua comunidade de origem, mas não os incomoda a "composição multinacional", por assim dizer, dessa comunidade. "Ao contrário", relata, eles inclusive tratam especialmente os jogadores "de fora" como uma espécie de "filhos adotivos" do time local. Essa projeção imaginária a partir da localidade corresponde à ideia de nação no mundo futebolístico profissional. Consequentemente, as equipes amadoras de futebol apresentam um efeito integrador para a comunidade hispânica sem desenvolver, explicitamente, o tema da multinacionalidade ou de uma identidade latinoamericana através do nome da equipe, do simbolismo visual ou de um nível discursivo qualquer.

A posição das mulheres no futebol, por seu turno, segue sendo marginal. No entanto, pela primeira vez em anos, algumas delas são dirigentes de equipes masculinas e chegaram a se organizar como jogadoras em clubes e ligas. Em 2002, por exemplo, fundou-se em Nova lorque uma liga feminina, a Liga de Futebol Internacional (International Soccer League), denominada de acordo com a homóloga masculina correspondente. Em 2003, competia nela o considerável número de 12 equipes. As jogadoras mexicanas, peruanas, equatorianas e de outros países latinoamericanos haviam imigrado aos EUA, em sua maioria, apenas há dez anos ou menos. Haviam, sobretudo, aprendido o futebol lá, uma vez que tal esporte era, em seus 
${ }^{60}$ Franziska CASTILLO, 2003.

${ }^{61}$ Gert EISENBÜRGER, 2006.

${ }^{62}$ SHINN, 2002, p. 242. países de origem, "tão guiado por testosterona e tão machista como o futebol americano nos próprios EUA", como explica uma jornalista a seus leitores, no jornal Puerto Rico Herald ${ }^{60} \mathrm{O}$ futebol feminino é tratado na vida pública de todos os países latino-americanos com negligência, à exceção do Brasil; por exemplo, a equipe nacional mexicana ocupa, atualmente, somente o $22^{\circ}$ lugar no ranking mundial da Fifa. ${ }^{61}$ Ao contrário, nos EUA, a maioria percebe o futebol como esporte feminino e, em nível mundial, as futebolistas americanas ocupam o segundo lugar, depois das alemãs.

As latinas, por sua vez, poderiam se orientar pelo futebol-modelo e desestabilizá-lo como "ritual masculino dado, que forma parte da socialização na América Latina". ${ }^{2}$ Não obstante, é indiscutível que durante muito tempo as mulheres foram marginalizadas no universo futebolístico dos migrantes, como já destacamos, pois nesse espaço se valorava a masculinidade, tanto na prática esportiva quanto nos "momentos de bebedeiras", após as partidas. Com as latinas não foi diferente. Infelizmente, a maioria das equipes e ligas seguem ainda mantendo uma divisão de papéis sexuais, integrando as latinas como não jogadoras, e sim como espectadoras, cozinheiras de quitutes em comemorações pós-jogos, recebedoras de donativos e, somente em casos individuais, como presidentas de clubes de futebol.

\section{A criação de uma equipe estadunidense autenticamente mexicana, a Chivas USA}

Desde sua fundação em 1996, a US Major League Soccer (MLS) está bastante interessada em romper a existência paralela dos mundos futebolísticos anglo-saxão e latino. E o que está por detrás dessa intenção, obviamente, são o interesse financeiro e a esperança de que, com a ajuda dos latinos, o país possa, finalmente, converter-se numa "nação do futebol". Entretanto, até agora a MLS não conquistou o público de quarenta milhões de hispânicos, apesar de muitas equipes profissionais americanas terem suas sedes em centros urbanos com forte presença latina e de também possuírem futebolistas mexicanos-americanos integrados em seus grupos. Com o intuito de atrair hispânicos à MLS, já foram investidos vários milhões de dólares em compra de superestrelas mexicanas, como o goleiro Jorge Campos e os goleadores Luis Hernández e Carlos Hermosillo. Além disso, em 2003 foi criada a liga juvenil Futebolito, exclusivamente para hispânicos. Contudo, tais medidas somente tiveram êxito moderado, causando o desespero dos administradores da MLS, dentre os quais se pode citar os empresários americanos Phil Anschutz, Lamar Hunt e Robert Kraft. Até agora somente os salvadorenhos e os bolivianos 
${ }^{63}$ Steven GOFF, 2005. (que vivem na região de Washington) converteram-se em aficionados pelas partidas da liga norte-americana de futebol. A grande maioria dos hispânicos (e sobretudo os torcedores fanáticos mexicanos) ainda prefere assistir no Univisión, ou em outros canais hispânicos, aos jogos de suas equipes favoritas da Primeira Divisão do Campeonato Mexicano de Futebol. ${ }^{63}$

Jorge Vergara é um empresário mexicano que conseguiu se converter em multimilionário mediante a venda de compostos vitamínicos e alimentos dietéticos em pó da marca Omnilife. Ganhou espaço na MLS quando apresentou sua última ideia empresarial, qual seja, incluir uma equipe adicional no conjunto das já existentes: seria, então, o retorno do Club Deportivo Guadalajara, popularmente conhecido como Chivas. Chivas - que é de propriedade de Vergara e, há algum tempo, um dos times de maior sucesso no México - é o carro-chefe esportivo da cidade de Guadalajara, capital de Jalisco, um dos principais estados emissores de emigrantes aos EUA.

Vergara, por sua vez, copiou muitos ingredientes dos amadores do hispanic soccer para uma receita de sucesso: apesar das restrições que a MLS impõe em relação ao número de jogadores estrangeiros em uma equipe, deu ao Chivas USA um caráter latino "mais autêntico", convocando prioritariamente jogadores hispânicos, compondo uma mescla de conhecidas estrelas do futebol mexicano, novos talentos norte-americanos de origem migrante, um ou outro brasileiro e/ou costarriquenho e outros quatro angloamericanos. Apesar disso, o idioma oficial da equipe é o espanhol e o grito de guerra autodenominador do grupo é "Adiós soccer. iEl fútbol está aquí!".

De forma calculada, integram-se particularidades do hispanic soccer em um novo pacote global, como a combinação do futebol com o trabalho comunitário: o Chivas USA dirige vários programas juvenis como forma de promover o futebol entre os adolescentes hispânicos e possui também um programa de caridade a crianças necessitadas. No que diz respeito às mulheres, o Chivas integra as jovens nos grupos de cheerleaders do clube e mantém um grupo júnior para as meninas.

A MLS aceitou tais inovações "revolucionárias" não apenas pelo fato de Vergara ter pagado US\$ 25 milhões pelos direitos da equipe. Ao lado desse forte componente, 0 time também possui outras estratégias de autocomercialização pelos meios de comunicação hispânicos, como o canal de televisão Univisión e mesmo o Los Angeles Times. Além disso, o empresário aposta na vinculação da equipe estadunidense com a de Guadalajara. "As camisetas de futebol, as cores, a tradição e a paixão", exclama o 
${ }^{64}$ CHIVAS USA, 2006.

milionário, teriam falado mais alto até agora na Major League. Por isso é que ele vestiu o Chivas USA com as mesmas cores da bem-sucedida equipe mexicana Chivas, resultando em camisetas de listras brancas e vermelhas alternadas, que, combinadas com o gramado verde, relembram as cores nacionais do México. Além do mais, nos arredores do estádio do clube em Los Angeles se pode também sentir um "clima mexicano", visto que no parque de diversões chamado ChivaTown - seguindo a publicidade da página na web - os torcedores e suas famílias podem "reviver a cidade de Guadalajara. Alí se encontram os arcos de Guadalajara, a [estátua] de Minerva, o Hall da fama 'Honda', o McDonalds 'FutZona', uma arena de entretenimento, comes e bebes, e muito mais". ${ }^{64}$

Tais promessas não são de todo falsas, pois também na cultura do futebol de Guadalajara se combinam as tradições mexicanas com os padrões de vida norteamericanos, sempre com vistas a gerar ganhos. Vergara promove atualmente a construção de um novo estádio de futebol para o Chivas (no México), em forma de vulcão. Esse é um dos pilares de uma "cidade do futuro" que está em gestação nos arredores de Guadalajara e na qual se buscará integrar os aspectos de conversação ambiental e de um discurso intelectual ao consumo e ao lazer em larga escala.

Foi com o Chivas USA que, pela primeira vez, se introduziu uma lógica de "nacionalidades" dentro da MLS. Seus inventores, no entanto, estão conscientes de que a criação de um cenário nacionalista mexicano não bastará para trazer ao Chivas USA uma legião diversa de fiéis mexicanos e um lugar de destaque dentro do futebol americano profissional. A equipe necessita conseguir triunfos esportivos. Para conquistá-los, mudou-se o treinador oficial em 2006 e se contratou o americano Bob Bradley. Com sua ajuda o time conquistou um respeitável terceiro lugar na porção oeste da Major League. Ainda que seja incerto como terminará o experimento Chivas USA, em um mundo globalizado os empresários e os meios de comunicação apostam no momento de transmitir, de maneira crível, novos localismos e nacionalismos orientados aos países latinoamericanos, incluindo, ao mesmo tempo, jogadores de outras filiações nacionais e hemisféricas, segundo critérios de desempenho esportivo. Tal receita de sucessos lhes fora ensinada pelos amadores do mundo esportivo.

\section{Considerações finais}

Na atualidade, o futebol latino está chamando muita atenção, visto que os migrantes hispânicos parecem difundir "seu esporte" paulatinamente nos EUA. Em consequência, 
muitos analistas esportivos interpretam o boom do futebol latino como uma sucessiva (re)conquista cultural dos EUA por parte dos mexicanos. Com o tema "Adiós soccer. iEl fútbol está aquí!", os diretores do Chivas USA comercializam a nova equipe profissional explicitamente como parte desse fenômeno.

A isso se pode agregar que os imigrantes mexicanos não deram - em todos os períodos históricos e por todos os meios relacionados ao futebol - expressão a uma "mexicanidade" transnacional e expansiva. Por outro lado, os atores sociais que expressaram (e ainda o fazem) certa "mexicanidade" não são, em seu conjunto, oriundos do México. A perspectiva histórica bem demonstrou que no transcurso do século XX estiveram (e estão) envolvidas dinâmicas complexas. O grupo dos imigrantes mexicanos e hispânicos é heterogêneo; muitos atores se reinventaram de diferentes maneiras por meio do futebol - de acordo com o período histórico e mesmo região onde se encontravam - e, assim, expressaram distintas formas de "mexicanidade". Algumas vezes foi destacada a rivalidade com imigrantes europeus (com os quais os mexicanos competem no mundo do trabalho), por meio de uma lógica esportiva nacional ou continental. Outras vezes, através do futebol, reforçaram-se papéis de gênero que predominavam na migração e no mundo masculinizado do trabalho. Em dados momentos, os atores - que se diferenciavam com respeito a seu pertencimento étnico, de gênero e de classe - buscavam, por meio das práticas futebolísticas, projetos de cunho comum: isso é válido para os torcedores e para os empresários de uma incipiente indústria étnica do lazer e dos meios de comunicação. No caso de Dalton (Geórgia), empresários não étnicos e trabalhadores mexicanos de baixos salários se comprometeram em favor de um futebol étnico local.

Desde os anos 1990, tanto grupos de hispânicos quanto os de não hispânicos serviram-se, em crescente proporção, do futebol como um recurso que constrói comunidade (principalmente no caso de novos imigrantes). Esses aproveitam o fato de que jogar e atuar em um mundo esportivo separado Ihes oferece boas opções de empoderamento. Por essa razão, recentemente tal experiência paralela está caracterizando o mundo amador e - com relação à simbologia de um pertencimento nacional - atualmente chegou também ao universo do futebol profissional dos EUA. Ao mesmo tempo, desde os anos 1990, os imigrantes mexicanos servemse do futebol como cenário-chave por meio do qual estendem uma vida transnacional de práticas e relações sociais que os vincula de maneira duradoura ao seu país de origem (no caso, o México). Com isso, expressam uma "mexicanidade transnacional" que não é "harmônica", e sim marcada por 
linhas de conflito, e que, portanto, se apresenta como uma mexicanidade frágil. Nessa "nova mexicanidade" manifestam-se conflitos de gênero, de classe e étnicos, locais e nacionais que se dão simultaneamente nos EUA e no México e que se influenciam mutuamente.

\section{Referências}

AGUILAR, Jesse. Año de El Nacional. 2006. Disponível em: <http://www.nuevosiglonews.com/moxie/sports/sports 1/ 2006-ao-de-el-nacional.shtml> . Acesso em: 2 jan. 2007.

ALAMILLO, José. "Peloteros in Paradise: Mexican American Baseball and Oppositional Politics in Southern California." In: IBER, Jorge; REGALADO, Samuel (Org.). Mexican Americans and Sports: A Reader on Athletics and Barrio Life. Texas: A \& M University Press, 2007. p. 50-72.

ALIANZA DEL FÚTBOL. Disponível em: <http://www.alianza defutbol.com/splash/>. Acesso em: 20 dez. 2006.

ARREDONDO, Gabriela; VAILLANT, Derek. "Mexicans." In: ENCYCLOPAEDIA OF CHICAGO. 2006. Disponível em: $<$ http://www.encyclopedia.chicagohistory.org/pages/ 824.html 2006>. Acesso em: 2 jan. 2007.

BASCH, Linda; SCHILLER, Nina Glick; BLANC, Cristina Szanton. Nations Unbound: Transnational Projects, Post Colonial Predicaments and Deterretorialized Nation States. Luxemburg: Routledge, 1994.

BOURDIEU, Pierre. "Programm für eine Soziologie des Sports". In: p. $\overline{193-207 .}$

Rede und Antwort. Frankfurt: Suhrkamp, 1992.

CASTILLO, Franziska. Not Just For Kicks: Hispanic Women Embrace Soccer League. 2003. Disponível em: <http:// www. puertorico-herald.org/issues/2004/vol8n 10/ NotJustKicks.shtml> . Acesso em: 2 jan. 2007.

CHIVAS USA. Disponível em: <http://chivas.usa.mlsnet.com/ †120/es/fans/>. Acesso em: 11 ago. 2006.

CHRON. Ad money not lost in translation. Disponível em: <http://www.chron.com/disp/story.mpl/sports/ 4425880.html >. Acesso em: 20 jan. 2007.

CITY PAPER. Disponível em: <http://www.citypaper.net/articles/ 2006-07-20/cb.shtm >. Acesso em: 8 out. 2006.

COHEN, Joel. For the Love of the Game: Latino Soccer Leagues in Somerville, Massachusetts. 2006. Disponível em: <http:/ /ase.tufts.edu/anthropology/faculty/pacini/students/ cohen.html>. Acesso em: 27 dez. 2006.

COPA LOWE'S. Disponível em: <http://www.hispanicprwire.com/ news.php? =in\&id=7802> . Acesso em: 11 nov. 2006.

COPA TECATE. El torneo amateur hispano más grande de Estados Unidos. Disponível em: <http://www.copa tecate.com/esp/interface.html>. Acesso em: 17 dez. 2006. 
EISENBÜRGER, Gert. "Förderung? Fehlanzeige! Frauenfußball in Lateinamerika". In: AZZELLINI, Darion; THIMMEL, Stefan (Org.). Fussball und Lateinamerika: Hoffnungen, Helden, Politik und Kommerz. Berlin: Assoziation A, 2006. p. 62-66.

ETECÉTERA. Andrés Manuel López Obrador y Carlos Slim. Disponível em: <http://www.etcetera.com.mx/articulo. php?articulo=3311>. Acesso em: 14 nov. 2006.

GOFF, Steven. MLS's New Club has a Mexican Upbringing. 2005. Disponível em: <http://www.washingtonpost.com/ ac2/wp-dyn/A17184-2005Mar31 ?language = printer $>$. Acesso em: 12 ago. 2005.

GUTIÉRREZ, David. "Migration, Emergent Ethnicity, and the 'Third Space': The Shifting Politics of Nationalism in Greater Mexico." The Journal of American History, v. 86, n. 2, p. 481-517, 1999. Special Issue: Rethinking History and the Nation-State: Mexico and the United States as a Case Study.

HERNÁNDEZ-LEON, Rubén; ZUÑIGA, Víctor. "Mexican Immigrant Communities in the South and Social Capital: The Case of Dalton, Georgia." In: . The Centre for Comparative Immigration Studies. San Diego: University of California, 2002. Working Paper 64.

HUNTINGTON, Samuel. Who are We? America's Great Debate. New York: Free Press, 2005.

IBER, Jorge; REGALADO, Samuel (Org.). Mexican Americans and Sports: A Reader on Athletics and Barrio Life. Texas: A \& M University Press, 2007.

JAMES, Cyril Lionel. Beyond a Boundary. London: Stanley Paul, 1963.

JONSSON, Patrik. Underground Soccer League Alters a Town. 2003. Disponível em: <http://www.csmonitor.com/2003/ 1126/p02s02-ussc.htm>. Acesso em: 30 dez. 2006.

KLEIN, Alan. Baseball on the Border: A Tale of two Laredos. Princeton: Princeton University Press, 1997.

MACCLANCY, Jeremy. "Sport, Identity and Ethnicity." In: MACCLANCY, Jeremy (Org.). Sport, Identity and Ethnicity. London: Routledge, 1996. p. 1-20.

MASSEY, Douglas et al. Return to Aztlán: The Social Process of International Migration from Western Mexico. Berkeley: University of California Press, 1987.

NSL CHICAGO. Disponível em: <http://nslchicagoo. web104.discountasp.net/1st_division.htm>. Acesso em: 20 dez. 2006.

PÉREZ, Louis. "Between Baseball and Bullfighting: The Quest for Nationality in Cuba 1888-1898." The Journal of American History, n. 81, p. 494-512, 1994.

PESCADOR, Juan Javier. "Vamos Taximaroa! Mexican/Chicano Soccer Associations and Transnational/Translocal Communities, 1967-2002." Latino Studies, n. 2, p. 352-376, 2004. 
. "Los Heroes del Domingo: Soccer, Borders, and Social Spaces in Great Lakes Mexican Commúnities, 19401970." In: IBER, Jorge; REGALADO, Samuel (Ed.). Mexican Americans and Sports: A Reader on Athletics and Barrio Life. Texas: A \& M University Press, 2007. p. 73-88.

REED, Matt. On Soccer Sundays, Hispanic Immigrants Crowd Parks Across Nation. 2006. Disponível em: <http://www. miami.com/mld/miamiherald/sports/15310570.htm >. Acesso em: 2 jan. 2007.

REGALADO, Samuel. Viva Baseball! Latin Major Leaguers and Their Special Hunger. Chicago: University of Illinois Press, 1998.

RILEY, Michael. Soccer Helps Arrivals to New Lives. 2003. Disponível em: <http://www.justicejournalism.org/projects/ riley-michael/riley-120103.pdf> . Acesso em: 2 jan. 2007.

RUSSAKOFF, Dale. U.S. Border Town, 1,200 Miles From the Border: Georgia's 'Carpet Capital' Relies on Immigrants. 2006. Disponível em: <http://www.washingtonpost.com/ wp-dyn/content/article/2006/07/16/!R20060716006>. Acesso em: 2 jan. 2007.

SHINN, Christopher. "Fútbol Nation. U.S. Latinos and the Goal of Homeland." In: HABELL-PALLÁN, Michelle; ROMERO, Mary (Ed.). Latino/a Popular Culture. New York University Press, 2002. p. 240-251.

SMITH, Robert. Mexican New York: Transnational Lives of New Migrants. Berkeley: University of California Press, 2005.

[Recebido em 10 de junho de 2011 e aceito para publicação em 30 de setembro de 2011]

\section{"Adiós soccer, here comes fútboll": Transnationalization of the Mexican Sports} Communities in the U.S.

Abstract: This article discusses the sport dynamics of the Mexican communities in the United States in the context of soccer. From the analysis of Mexican groups which immigrated to the American territory, and from their soccer practices (of resistance), this research questions whether we would be witnessing a sportive "Iatinoamericanization" of the U.S. through the soccer practices. As a counter-response to a homogenization and subordination, the Mexican Americans (and, by extension, the Latinos in general) have created new cultural practices (and, among them sportive ones) that put together Mexican traditions with American values of society constituting, in that way, "a third space", which extends beyond the borders of both national States. This paper, therefore, examines why a growing number of migrants strengthens relationships with their communities of origin in Mexico through the (re)creation of a soccer world itself, expressing thereby a "transnational mexicanity", which is not "harmonic" by itself, but marked by conflicts. In this "new mexicanities" gender, class and ethnic, national and local conflicts - which occur simultaneously in the U.S. and Mexico, influencing each other-appear.

Key Words: Hispanic Soccer; International Migration; Transnationalization; "Mexicanities". 